\title{
New Insights in Plant Breeding Efforts for Improved Salt Tolerance
}

\section{Michael C. Shannon ${ }^{1}$}

Additional index words. salinity, management, irrigation, genetic selection, systems research

Summary. The lack of improvement for salt tolerance has been attributed to insufficient genetic variation, a need for rapid and reliable genetic markers for screening, and the complexities of salinity $\times$ environment interactions. Salt tolerance is a quantitative characteristic that has been defined in many ways subject to changes with plant development and differentiation; thus, assessing salt tolerance among genotypes that differ in growth or development rate is difficult. Salt tolerance also varies based on concentrations of major and minor nutrients in the root zone. Plant growth models may provide a method to integrate the complexities of plant responses to salinity stress with the relevant environmental variables that interact with the measurement of tolerance. Mechanistic models have been developed over the last few years that are responsive to nitrogen or drought stress but not to salinity stress. Models responsive to salinity stress would provide insights for breeders and aid in developing more practical research on the physiological mechanisms of plant salt tolerance. 
dealing with salinity. When high-quality water is not available for irrigation and leaching, crop substitution has been the main approach to dealing with salinity. More salt-tolerant crops are substituted for salt-sensitivespecies. Thus, barley may be substituted for wheat, cotton for corn, sugar beet for lettuce, etc. Unfortunately, most vegetable crops are more sensitive to salt than most field crops. Harvest quality usually has a more significant impact on marketable yield of horticultural crops than field crops. The salt-tolerance tables developed by the U.S. Salinity Laboratory have been valuable guides for extension personnel and growers in determining which crops can be grown based on the expected soil salinity (Maas, 1990; Maas and Hoffman, 1977).

Agromanagement techniques that minimize and avoid salinity effects include leaching, deep plowing, applying amendment and carefully choosing fertilizer sources, installing drainage, land leveling, and irrigation technologies. Other management options include using drip or sprinkler irrigation to improve water application efficiency and elaborations in bed formation and planting design to facilitate removal of accumulated salts from the areas in which roots are developing and extracting water (Rhoades, 1993). Somestrategies that have not been adequately researched involve manipulating population densities to improveplant stand and applying nonsaline or more saline water dependent on variable salt tolerance with growth stage.

More recently, crop breeding and genetic manipulation, using tools such as tissue culture and molecular biology, have been proposed as adjunct strategies to deal with salinity. Past work has shown that different crop species vary with respect to at least two of their parameters of salt tolerance - the salt tolerance threshold and yield declinebeyond that threshold (Maas and Hoffman, 1977). These parameters reflect the simplest way to conceptualize the effects of salt on yield.

In the last 2 decades there has been great interest in breeding plants for improved salt tolerance(Shannon, 1979; Shannon and Noble, 1990). Strategies that have been tried or suggested includeconventional screening, selecting and breeding with established cultivars, introducing high salt tolerance in cultivated species through introgression with tolerant wild relatives, or domesticating salt-tolerant wild or halophytic species through the genetic improvement of agronomic or horticultural characteristics. Some of these efforts have resulted in limited success but major advances have not been noted.

Examples of screening or selection criteria that have been tried include selection during germination or emergence, resistance to salinityinduced reductions in plant height or weight, and maintenance of high yield or quality under salt stress and plant survival (Shannon and Noble, 1990). Extensive efforts have also been made to identify reliablephysiological or biochemical mark- ers for salt tolerance. These markers include exclusion of ions $(\mathrm{Na}, \mathrm{Cl})$ from shoots or specific tissues, maintenance of nutrients $(\mathrm{K}, \mathrm{Ca}, \mathrm{Mg}, \mathrm{P}$, $\mathrm{NO}_{3}$ ), and ion selectivity (high $\mathrm{KNa}, \mathrm{Ca} / \mathrm{Na}$, or $\mathrm{NO}_{3} / \mathrm{Cl}$ ratios) (Cheeseman, 1988; Jeschke, 1984; Shannon, 1979, 1982). Accumulated metaboliccompatiblesolutes such as proline, glycinebetaine, and certain sugars and alcohols have also been proposed as indices for high salt tolerance, but the evidence that accumulation of compatible solutes offers a quantitatively measurable improvement in salt tolerance has not been universally accepted .

Physiologists have offered even more complex criteria for salt tolerance. Some of these include the ability of some species or varieties to maintain membrane integrity due to component structure or the ability to sequester ions viacompartmentation, excrete ions through salt glands, or dilute ions using succulence (Lüttge and Smith, 1984; Thomsom et al., 1988). Some proposed morphological adaptations for salt tolerance include change in root-to-shoot ratio, rosette growth, succulence, reduction of stature through shoot or tiller abortion, and early initiation of reproductivegrowth (Läuchli and Epstein, 1990; Maas and Grieve, 1990; Maas and Nieman, 1978). Metabolic adaptations that have been associated with tolerance include increased respiration and improved water use efficiency at low salinity levels, increased mesophyll resistance, decreased $\mathrm{CO}_{2}$ fixation, synthesis of compatible organic solutes, and the initiation of CAM metabolism (Lüttge and Smith, 1984; Shannon et al., 1994). It may not be obvious, but reduced growth rate, in itself, may be an adaptation to high salinity. A smaller plant requires less water and does not concentrate excluded salts in the root zone to the same extent as a plant that maintains a more rapid growth rate.

At least three dogmas have been established with respect to salinity stress. First, salinity is a multicomponent stress in aphysical and chemical sense and varies in intensity over the three dimensions of space, time, and concentration. Its effects depend on specific salt composition and are subject to environmental interactions. The second dogmais that within the plant kingdom thereexists a vast array of adaptive responses to salinity stresses. The physiological significance or quantitative importance of most of these has not been explicitly proven or quantitatively described and will continue to be a major research objective. A third well-known dogma is that salinity stress is highly sensitive to interactions with other environmental variables, especially humidity and light intensities (Magistad et al., 1943; Salim, 1989).

The complexities intertwined in the aforementioned dogmas highlight theneed for amethod of conceptual integration. Within the last 50 years much information has been developed concerning salt tolerance and effects of salinity on plants or plant components. However, the component observations and facts constitute a hodgepodge that resists comprehension. A new impetus is needed to advance breeding for salt tolerance to a higher level. Two technologies that will be useful in the breeding effort are crop modeling and systems methodology. Process-based plant growth models help simulate complex crop responses to salinity in an integrativemanner over different growth stages and soil-environment scenarios. Although mechanistic models responsive to salinity stress are just beginning to be developed, there is reasonable hope that such models will soon provide anew basis for testing hypotheses and experimental design. Most existing plant growth models treat the soil simplistically. Integrated soil chemistry and physics models that describewater movement and chemical interactions are available (Simunek et al., 1992; Suarez and Simunek, 1994), but these models treat the plant in a simplistic manner and incorporate the effects of salinity through empirical rather than mechanistic relationships. These models oversimplify calculations for yield and root water uptake. Second-generation models that address and correct some of these problems are currently being developed. These models will be developed to handle salinity stress in a more mechanistic and comprehensive manner, including differential salt sensitivity relative to growth stage and a better coupling of growth and root water uptake with above-ground plant growth and development.

Systems approaches also provide an opportunity to coalesce and use efficiently available technology and the accumulated knowledge concerning salt tolerancethat has been obtained in the last 2 decades (Shannon, 1994; Wymore, 1993). System approaches as applied to the development of salt tolerance include the following:

1) Defining the problem;

2) Establishing inputs and outputs;

3) Identifying requirements for performance and resource use;

4) Assessing available technology;

5) Developing a solution concept; and

6) Developing screening and selection procedures that will lead to a plant ideotype to fit the prescribed requirements of theagronomic system.

The problem to be definedis the specific salinity problem that is being addressed in the context of crop species, agricultural environment, and specific ion and toxicity thresholds during cropping. This requires significantinputfrom growers and produce buyers. A description of the salinity situation should include source of salinity (e.g., irrigation water, soil, water table), salt-specific ion distribution and concentration information, and environmental factors such as range of affected crop land, climate, soil type, and drainage availability.

Genetic variability should be assessed to determine the extent to which cultivars express a salt tolerance that might prove useful for the problem being considered. This assessment should include the known salinity threshold, yield decline 
parameters for the crop, and information on intervarietal and interspecific variability. Also, information should be collected on known interactions among salinity responses and other environmental variables. Available physiological or morphological mechanisms with importance for salt tolerance should be noted.

Accuratly defining the problem is essential for establishing input and output requirements. Assessments should be made with regard to the economic situation and genetic variability. The economic situation should be appraised with consideration to costs to the grower, such as seed, water fertilizer, chemicals, field operations, fuel, labor, and overhead. Such costs should beweighed against market considerations (e.g., yield, quality, earliness), allotments and price supports, and indirect effects, such as long range sustainability or potential of using and generating saline drainage or groundwater.

Performance and resource use requirements must be identified at this juncture. Crop yield and quality requirements should be defined and fixed costs for production should be specified. Managementoptions should beweighed against breeding potential. If management is a relatively inexpensive input into the system, then perhaps a full-scale breeding effort is not needed. If using saline water is a requirement, adequate genetic variability must be potentially available to produce a crop that is economically successful. For efforts that require management and breeding, for example, tolerance at specific growth stages should be identified. The magnitude of increase in salt tolerance needed to achieve success should be identified.

Available technology must be assessed to determine the types of germplasm and equipment that are available. Salt-tolerant rootstocks have been identified for a number of woody species, including citrus, grape, avocado, and stonefruits (Maas, 1986). Cultivars of lettuce, tomato, melon, and several other crops that have greater relative salt tolerances than others have been identified (Shannon and Francois, 1978; Shannon and Noble, 1990; Shannon et al., 1983). In some instances, a closely related salt-tolerant species might be useful in place of a more sensitive species; for instance, cantaloupe might be used instead of watermelon, or a salt-tolerant forage such as tall wheatgrass or subterranean clover might replace crested wheatgrass or white clover (Shannon, 1978; Shannon and Noble, 1995). Salt-tolerant lines may be incorporated into the overall strategy as substitutes for sensitive cultivars or species or as potential parents in acrossing and selection program designed to achievegreater salt tolerance.

The next step is to develop a solution concept. The essence of this is to develop a functional conceptual model of the plant ideotype that will fill the niche in a described agromanagement system, a system that will fulfill all of the established requirements. Crop growth simulation models may someday be useful in hypothesistesting of such ideotypes beforescreening and selection technologies are used in a fullscale breeding program.

The concept of the ideotype can be used to develop screening and selection procedures. The screening program may befocused on a selected combination of physiological and morphological characters that are predicted to best fit a proposed management system in the target environment. Any combination of technologies from conventional breeding to molecular approaches might be used to achieve the desired ideotype. After the desired genotype is obtained through any procedure, it is important that procedures be established for germplasm maintenance and protection and future varietal improvement and development. Otherwise, the unique combinations that infer salt tolerance with the specific target environment cannot be expected to endure growth stages (Shannon, 1985).

Many successful plant breeders are able to conceptualize intuitively the steps that have been outlined herein to produce successful cultivars in nonsaline situations; however, salinity problems associated with irrigated agriculture are complex and require a more rigorous and structured effort. The lack of such a structured effort has contributed as much to the lack of progress in breeding for salt tolerance as have previous gaps in information concerning salt tolerance mechanisms.

\section{Literature Cited}

Cheeseman, J.M. 1988. Mechanism of salinity tolerance in plants. Plant Physiol. 87:547-550.

Jeschke, W.D. 1984. K+-Na+ exchangeat the cellular membranes, intercellular compartmentation of cations and salt tolerance, p. 37-66. In: R.C. Staples and G.H. Toenniessen. (eds.). Salinity tolerance in plants: Strategies for crop improvement. Wiley, New York.

Läuchli, A. and E Epstein. 1990. Plant responses to salineand sodic conditions, p. 113-137. In: K.K. Tanji. (ed.).Agricultural salinityassessmentandmanagement. Amer.Soc. Civil Eng. ManualsRot. Eng.PracticeNo.71. Amer. Soc. Civil Eng., New York.

Lüttge, U. and J.A.C. Smith. 1984. Structural, biophysical, and biochemical aspects of therole of leaves in plant adaptation to salinity and water stress, p. I25-150. In: R.C. Staples and G.H. Toenniessen. (eds.). Salinity tolerance in plants: Strategies for crop improvement. Wiley, New York.

Maas, E.V. 1986. Salt tolerance of plants. Appl. Agr. Res. 1:12-26.

Maas, E.V. 1990. Crop salt tolerance, p. 262-304.
In: K.K. Tanii. (ed.). Agricultural salinity assessment and management. Amer. Soc. Civil Eng. Manuals Rpt. Eng. Practice No. 71. Amer. Soc. Civil Eng., New York.

Maas, E.V. and C.M. Grieve. 1990. Spike and leaf development in salt-stressed wheat. Crop Sci. 30:1309-1313.

Maas, E.V. and G.J. Hoffman. 1977. Crop salt tolerance - Current assessment. J. Irr. Drainage Div., Amer. Soc. Civil Eng. 103(IR2):115-134.

Maas, E.V. and R.H. Nieman. 1978. Physiology of plant toleranceto salinity. In: G.A. Jung (ed.). Crop toleranceto suboptimal land conditions. ASASpec. Publ. 32:277-299.

Magistad, O.C., A.D. Ayers, C.H. Wadleigh, and H.G. Gauch. 1943. Effect of salt concentration, kind of salt, and climate on plant growth in sand cultures. Plant Physiol. 18:151-166.

Rhoades, J.D. 1993. Practices to control sal inity in irrigated soils, p. 379-387. In: H. Lieth and A. Al Massoum (eds.). Towards tational use of high salinity tolerant plants. vol 2. Proc. 1st ASWAS Conf. 8-15 Dec. 1990, Al Ain Univ, United Arab Emirates, Kluwer Acad. Publ., Dordrecht.

Salim, M. 1989. Effects of salinity and relative humidity on growth and ionic relations of plants. New Phytol. 113:13-20.

Shannon, M.C. 1978. Testing salt tolerance variability among tall wheatgrass lines. Agron. J. 70:719-722.

Shannon, M.C. 1979. In quest of rapid screening techniques for plant salt tolerance. HortScience 14:587-589.

Shannon. M.C. 1982. Genetics of salt tolerance: New challenges, p. 271-282. In: A. San Pietro (ed.). Biosaline research: A look into the future. Plenum Publ. Corp.

Shannon, M.C., J.D. McCreight, and J.H. Draper. 1983. Screening tests for salt tolerance in lettuce. J. Amer. Soc. Hort. Sci. 108:225-230.

Shannon. M.C. 1985. Principles and strategies in breeding for higher salt tolerance. Plant Soil $89: 227-241$.

Shannon, M.C. 1987. Salinity-An environmental constraint on crop productivity, p. 9-18. 4th Austral. Agron. Soc. Conf., Responding to Change, LaTrobe, Univ., Melbourne, Australia, 24-27 Aug.

Shannon, M.C. 1994. Development of salt stress tolerance-Screening and selection systems for 
geneticimprovement, p. 117-332. In:V.C. Baligar, R.R. Duncan, and J. Maranville (eds.). Proc. Workshop on Adaptation of Plants to Soil Stresses, Sorghum and Millet Collaborative Support Program (INTSORMIL), Univ. of Nebraska, 1-4 Aug. 1993.

Shannon, M.C. and L.E. Francois. 1978. Salt tolerance of threemuskmelon cultivars. J. Amer. Soc. Hort. Sci. 103:127-130.

Shannon, M.C., C.M. Grieve, and L.E. Francois. 1994. Whole plant response to salinity, p. 199244. In: R. E. Wilkinson (ed.). Plant response mechanisms to the environment, Marcel Dekker, New York.

Shannon, M.C. and C.L. Noble. 1990. Genetic approaches for developing economic salt-tolerant crops, p. 161-185. In: K.K. Tanji. (ed.). Agricultural salinity assessment and management. Amer. Soc. Civil Eng. Manuals Rpt. Eng. PracticeNo. 71. Amer. Soc. Civil Eng., New York.

Shannon, M.C. and C.L. Noble. 1995. Variation in salt tolerance and ion accumulation among subterranean clover cultivars. Crop Sci. 35:798-804.

Simunek, J., T. Vogel, and M. Th. van Genuchten. 1992. The SWMS_2 code for simulating water flow and solutetransport in two-dimensional variably saturated media. version 1.1. Res. Rpt. No. 126, U.S. Salinity Lab., Riverside, Calif.

Suarez, D.L. and J. Simunek. 1994. Modeling equilibrium and kinetic major ion chemistry with $\mathrm{CO}_{2}$ production/transport coupled to unsaturated water flow, p. 1215-1246. In: Gee and N.R. Wing (eds.). In situ remediation: Scientific basis for current and future technologies. Part 2, G.W. 33rd Hanford Symp. on Health and the Environment, Pasco, Wash.

Thomson, W.W., C.D. Faraday, and J.W. Oross. 1988. Salt glands, p. 498-537. In: D.A. Baker and J.L. Hall (eds.). Solute transport in plant cells and tissues. Longman Scientific \& Technical, Harlow, Essex, England.

Wymore, A.W. 1993. Model-based systems engineering. CRC Press, Boca Raton, Fla.

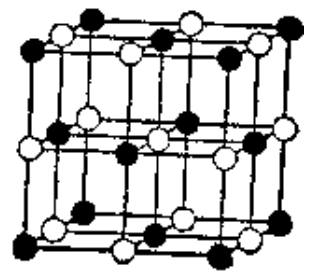

